\title{
ENZYME ANALYSIS OF THE TRYPTOPHAN PATHWAY IN ASPERGILLUS NIDULANS ${ }^{1}$
}

\author{
R. HÜTTER ${ }^{2}$ AND J. A. DEMOSS \\ Department of Biology, Revelle College, University of California, San Diego, \\ La Jolla, California 92037
}

Received August 30, 1966

\begin{abstract}
$T^{\mathrm{H}}$
HE five sequential enzyme reactions which lead to the biosynthesis of tryptophan are essentially identical in Escherichia coli, Neurospora crassa, and Saccharomyces cerevisiae. In contrast, marked differences have been found in the number of demonstrable protein components which catalyze these five reactions and in the number of genetic loci controlling the pathway (Table 1). The differences in the number of protein components involved in the pathway are due to the occurrence of enzyme aggregates which catalyze more than one reaction (Bonner, DeMoss and Mills 1965; DeMoss 1965).

In Aspergillus nidulans RoBerTs (1967) found five different groups of mutants requiring tryptophan for growth. An analysis of some of the tryptophan mutants of $A$. nidulans was made in order to ascribe the control of the enzyme activities to specific genetic loci. Additional zone centrifugation experiments
\end{abstract}

TABLE 1

Comparison of the number of genes and demonstrable protein components in the tryptophan pathway

\begin{tabular}{|c|c|c|c|}
\hline Organism & $\begin{array}{l}\text { Number } \\
\text { of genes }\end{array}$ & $\begin{array}{l}\text { Number of } \\
\text { demonstrable } \\
\text { protein } \\
\text { components }\end{array}$ & References \\
\hline Escherichia coli & 5 & 5 & $\begin{array}{l}\text { YANOFSKY and LENNOX (1959), } \\
\text { MATSUSHIRO (1963), } \\
\text { ITo and CraWFORD (1965), } \\
\text { BoNNER, DeMoss and MiLLs (1965), } \\
\text { DEMoss (1965) }\end{array}$ \\
\hline Saccharomyces cerevisiae & 5 & 4 & $\begin{array}{l}\text { Mortimer and Hawthorine (1966), } \\
\text { Bonner, DeMoss and Mrlls (1965), } \\
\text { DeMoss (1965) }\end{array}$ \\
\hline Neurcspora crassa & 4 & 3 & $\begin{array}{l}\text { Ahmad and Catcheside 1960), } \\
\text { Bonner, DeMoss and Mills (1965), } \\
\text { WEgman (1964), } \\
\text { WEgman and DeMoss (1965), } \\
\text { DeMoss (1965) }\end{array}$ \\
\hline
\end{tabular}

\footnotetext{
1 This work was supported by a grant from the National Science Foundation (GB-4687).

${ }^{2}$ Postgraduate Research Fellow of the Federal Technical Institute Zürich, Switzerland. 
were carried out to study the possible occurrence of enzyme aggregates. Thus, similarities with the previously discovered types of gene-enzyme relationships and peculiarities of the $A$. nidulans system could be analyzed.

\section{MATERIALS AND METHODS}

Organisms: A selection of tryptophan mutants derived from the parental strain Aspergillus nidulans Al60 (RoBERTs 1967) was chosen for our studies.

Culture and preparation of extracts: The strains were grown on minimal medium (Voget 1956) supplemented with $10 \mathrm{~g} / \mathrm{l}$ dextrose, $10 \mathrm{~g} / \mathrm{l}$ Bacto-peptone (Difco) and $4 \mathrm{~g} / 1$ Bacto-yeast extract (Difco); in order to reduce traces of bacterial contaminations, $50 \mathrm{mg} / 1 \mathrm{chloramphenicol}$ was added.

Heavy spore suspensions were made in sterile distilled water from slants, maintained by the method of RoBerTs (1967) and Fermbach flasks containing $1 \mathrm{l}$ of medium were inoculated with approximately $5 \mathrm{ml}$ of spore suspension. The flasks were incubated on a rotary shaker at $30^{\circ} \mathrm{C}$ for 1 to 2 days to guarantee heavy growth. The mycelium was harvested by filtration, carefully washed and lyophilized. The dry material was ground to a fine powder for preparation of extracts.

For investigations of the enzymes anthranilate synthetase, PR-transferase, ${ }^{3}$ PRA isomerase and InGP synthetase, the powder was stirred for 15 minutes in an ice bath with 15 volumes of 0.05 m potassium phosphate buffer, $\mathrm{pH} 7.0$. The crude extract was prepared by centrifugation of this suspension at $13,000 \times \mathrm{g}$ for 20 minutes to remove cell debris. For the study of tryptophan synthetase the powder was extracted with the buffer used by ENSIGN, KapLaN and BoNNER (1964), but otherwise the treatment was the same.

For zone centrifugation experiments it was necessary to use concentrated and partially purified preparations. The crude extracts were first treated with protamine sulfate (YANOFsK Y 1955). $24.23 \mathrm{~g}$ of solid ammonium sulfate was added per $100 \mathrm{ml}$ of protamine sulfate supernatant solution which was stirred for 15 minutes in an ice bath and centrifuged for 15 minutes at $13,000 \times g$. The precipitate was dissolved in $0.1 \mathrm{M}$ potassium phosphate buffer, $\mathrm{pH} 7.8$, containing $4 \times 10^{-5} \mathrm{M}$ pyridoxal phosphate, $2 \times 10^{-3} \mathrm{M}$ DL-serine and $10^{-3} \mathrm{M}$ EDTA. To the supernatant $6.27 \mathrm{~g}$ solid ammonium sulfate was added and the solution was treated as above. The precipitate was dissolved in $0.05 \mathrm{~m}$ potassium phosphate buffer, $\mathrm{pH}$ 7.0. The dissolved ammonium sulfate fractions together with an aqueous crystalline catalase suspension (Worthington) was layered on linear $5-20 \%$ sucrose gradients prepared with the appropriate buffers. The tubes containing the gradients were centrifuged at $39,000 \mathrm{rpm}$ in the SW 39 head of a Spinco Model L centrifuge for approximately 11 hours. Twelve-drop fractions were collected, diluted and assayed for catalase (on $405 \mathrm{~m} \mu$ ) and for enzyme activities.

Assays: Anthranilate synthetase was tested as described by DEMoss (1965), and InGP synthetase was analyzed following the procedure of WEGMAN and DEMoss (1965). PR-transferase was assayed by following anthranilic acid disappearance directly in an Aminco Bowman Spectrophotofluorometer in the following incubation mixture: $100 \mu$ moles potassium phosphate buffer, $\mathrm{pH} 8.0 ; 5 \mu$ moles $\mathrm{MgSO}_{4} ; 0.01 \mu$ moles anthranilic acid and $0.3 \mu$ moles PRPP with the addition of 1.0 unit of a partially purified InGP synthetase preparation from Neurospora crassa in a final volume of $1.0 \mathrm{ml}$ at $37^{\circ} \mathrm{C}$. PRA isomerase was assayed at $37^{\circ} \mathrm{C}$ in a reaction mixture containing $100 \mu$ moles potassium phosphate buffer, $\mathrm{pH} 8.0 ; \mu$ moles $\mathrm{MgSO}_{4} ; 0.15 \mu$ moles anthranilic acid, 0.7 $\mu$ moles PRPP and 2 units of a partially purified preparation of PR-transferase from $N$. crassa in a final volume of $1 \mathrm{ml}$. At zero time and at the end of the incubation period (10 minutes) $0.4 \mathrm{ml}$ of the reaction mixture was removed to tubes containing $0.2 \mathrm{ml}$ of $1 \mathrm{~N}$ acetic acid, which were incubated for 2 minutes at $37^{\circ} \mathrm{C}$, to convert all PRA present to anthranilic acid. The samples were

3 The following abbreviations are used:

CDRP, 1-(o-carboxyphenylamino)-1-deoxyribulose-5-phosphate

InGP, indole-3-glycerolphosphate

PRA, N-(5'-phosphoribosyl) anthranilic acid

PRPP, 5-phosphoribosyl-1-pyrophosphate

PR-, phosphoribosyl- 
cooled in an ice bath and extracted with $5.0 \mathrm{ml}$ ethyl acetate and the ethyl acetate extracts were measured for anthranilic acid in an Aminco Bowman Spectrophotofluorometer. The disappearance of anthranilic acid is a measure of PRA isomerase activity. For tryptophan synthetase the method of YaNofsky (1955) was used with the exception that the potassium phosphate buffer was replaced by Tris(hydroxymethyl)aminoethane- $\mathrm{HCl}, \mathrm{pH} 7.8$ (final concentration in incubation mixture $0.1 \mathrm{M}$ ), and $0.03 \mathrm{ml}$ saturated potassium chloride solution was added per ml incubation mixture. Protein was assayed according to the procedure of Lowry, Rosenbrough, Farr and RANDALL (1951). In each assay, a unit is defined as that amount of enzyme which catalyzes the formation of $1 \mu$ mole of product per hour.

\section{EXPERIMENTAL RESULTS}

The presence of all five enzyme reactions of the tryptophan pathway was demonstrated in the parental strain, A160, by an analysis of crude extracts. A variety of enzymatic defects was found in the representatives of the different mutant classes (Table 2). Mutant classes A, B and D each lack a single enzymatic activity; class A lacks anthranilate synthetase, class B lacks tryptophan synthetase and class D lacks PR-transferase. Class $C$ is more complex, in that three of the four strains examined lack anthranilate synthetase and PRA isomerase as well as InGP synthetase. The fourth mutant of this class, C647, lacks InGP synthetase but retains anthranilate synthetase and PRA isomerase. Unexpectedly, the representatives of mutant class $\mathrm{E}$, although they require tryptophan for their growth, did not lack any of the enzymatic activities tested, but all reaction were catalyzed at rates similar to those of the parental strain.

The occurrence of multiple effects in $\mathrm{C}$ class mutations suggested, in analogy to the $N$. crassa system, the presence of an enzyme aggregate. Therefore, the

\section{TABLE 2}

Enzyme activities of strains of Aspergillus nidulans (activities expressed in umoles per hour per mg of protein)

\begin{tabular}{|c|c|c|c|c|c|c|}
\hline & Strain no. & $\begin{array}{c}\text { Anthranilate } \\
\text { synthetase }\end{array}$ & $\begin{array}{c}\text { PR- } \\
\text { transferase }\end{array}$ & $\underset{\text { isomerase }}{\text { PRA }}$ & $\underset{\text { synthetase }}{\text { InGP }}$ & $\begin{array}{l}\text { Tryptophan* } \\
\text { synthetase }\end{array}$ \\
\hline Parental: & $\mathrm{A} 160$ & 0.06 & 0.20 & 0.78 & 0.13 & + \\
\hline \multirow[t]{3}{*}{ Mutant class A: } & A21 & 0.00 & 0.21 & 1.27 & 0.24 & + \\
\hline & A 459 & 0.00 & 0.18 & 1.59 & 0.14 & + \\
\hline & $\mathrm{A} 622$ & 0.00 & 0.08 & 1.87 & 0.18 & + \\
\hline \multirow[t]{2}{*}{ Mutant class B: } & B 26 & 0.07 & 0.20 & 0.83 & 0.25 & 0 \\
\hline & B 479 & 0.02 & 0.19 & 1.45 & 0.17 & 0 \\
\hline \multirow[t]{4}{*}{ Mutant class $\mathrm{C}$ : } & $\mathrm{C} 473$ & 0.00 & 0.18 & $<0.01$ & 0.00 & + \\
\hline & C485 & 0.00 & 0.12 & 0.00 & $<0.01$ & + \\
\hline & C612 & 0.00 & 0.14 & 0.00 & 0.00 & + \\
\hline & C 647 & 0.03 & 0.06 & 0.70 & 0.00 & + \\
\hline \multirow[t]{2}{*}{ Mutant class D: } & $\mathrm{D} 462$ & 0.06 & 0.00 & 1.58 & 0.11 & + \\
\hline & D554 & 0.03 & 0.00 & 0.79 & 0.07 & + \\
\hline \multirow[t]{3}{*}{ Mutant class E: } & E 17 & 0.15 & 0.22 & 1.01 & 0.17 & + \\
\hline & E 542 & 0.06 & 0.14 & 0.48 & 0.05 & + \\
\hline & E 646 & 0.04 & 0.07 & 1.33 & 0.13 & + \\
\hline
\end{tabular}

* Because tryptophan synthetase is very unstable in extracts of $A$, nidulans, reproducible quantitation of this assay was difficult. Therefore, only qualitative results are presented for this enzyme. 


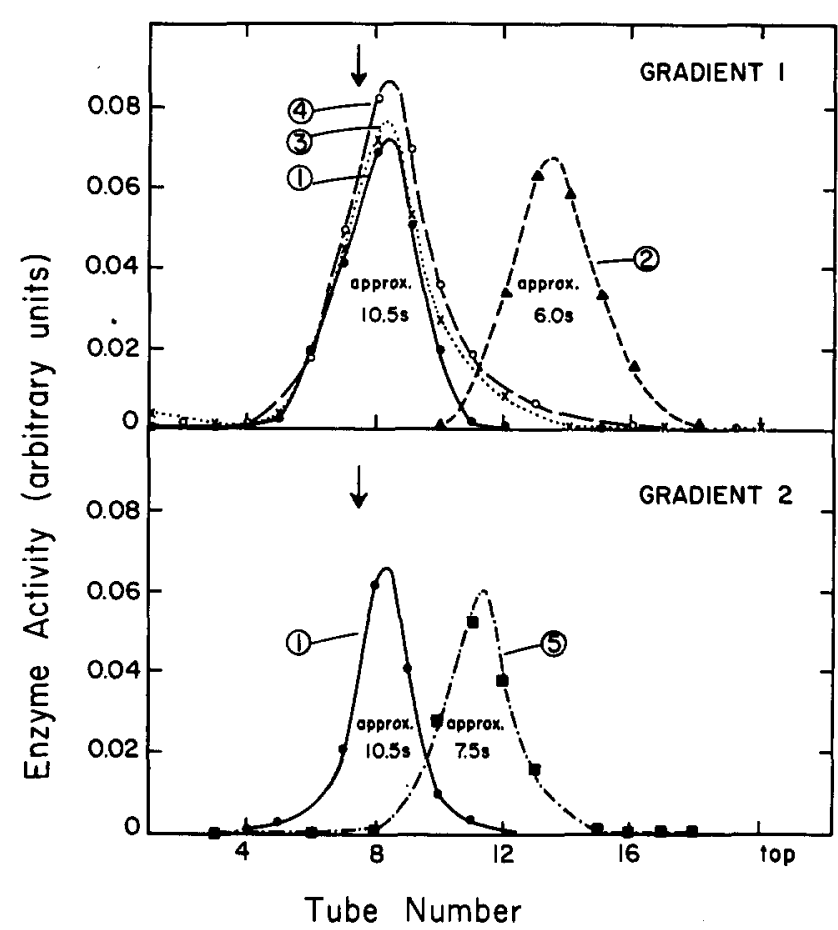

FIGURE 1.-Activity profiles after zone centrifugation of the parental strain, Aspergillus nidulans A160. Gradient 1: $0.2 \mathrm{ml}$ of 40-50\% ammonium sulfate fraction plus $0.1 \mathrm{ml}$ catalase. Gradient 2: $0.2 \mathrm{ml}$ of $0-40 \%$ ammonium sulfate fraction plus $0.1 \mathrm{ml}$ catalase. Arrow indicates position of catalase. Enzyme activities: (1) anthranilate synthetase; (2) PR-transferase; (3) PRA isomerase; (4) InGP synthetase; (5) tryptophan synthetase. The absolute activities in the peak tubes are anthranilate synthetase 7.6 units $/ \mathrm{ml}$, PR-transferase 12.8 units $/ \mathrm{ml}$, PRA isomerase 33.2 units $/ \mathrm{ml}$, InGP synthetase 17.2 units $/ \mathrm{ml}$, tryptophan synthetase 2.5 units $/ \mathrm{ml}$. Sedimentation coefficients $S$ estimated by the relative position of the peak of the activity profile to the peak of the profile of the catalase marker.

tryptophan enzymes of the parental strain, A160, were examined by zone centrifugation (Figure 1). The enzyme activity profiles show the presence of a common band of anthranilate synthetase, PRA isomerase and InGP synthetase with a sedimentation coefficient of about 10.5S. A separate activity band is found for tryptophan synthetase with a sedimentation coefficient of about $7.5 \mathrm{~S}$ and a third band of about $6.0 \mathrm{~S}$ contains PR-transferase. The same pattern was found in a zone centrifugation analysis of a representative of the $\mathrm{E}$ mutant class, strain E542.

\section{DISGUSSION}

The genetic control of the enzymatic activities in the tryptophan pathway of Aspergillus nidulans has some complex aspects. In some instances a simple one gene-one enzyme relationship can be established. In other cases a single gene appears to control more than one enzymatic activity and a single enzymatic activity seems to be subjected to influences from more than one gene. These 


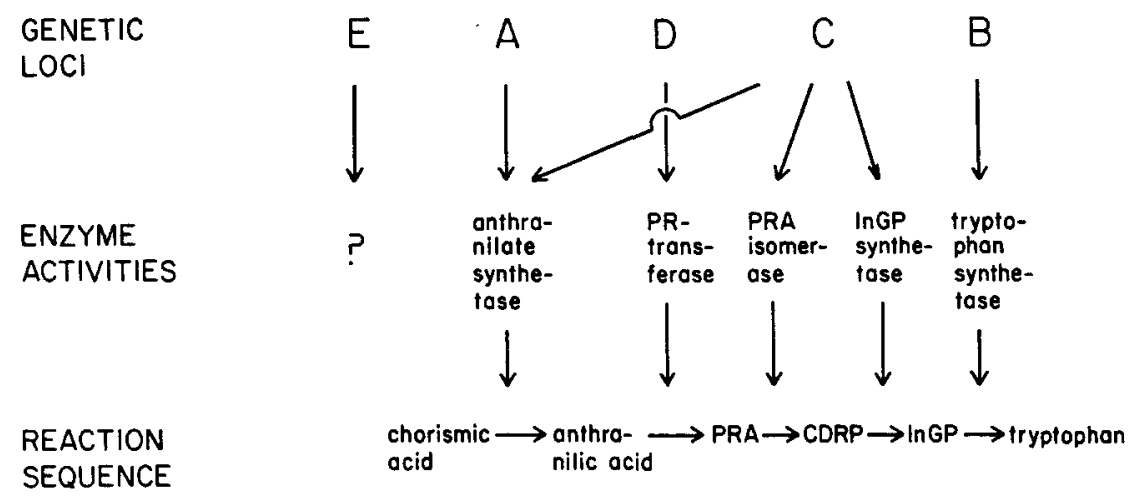

FIGURE 2.- The genetic control of the tryptophan pathway in Aspergillus nidulans strain A160.

relationships are summarized in Figure 2. The relationships found for mutant classes A, B, C and D indicate the analogy of the $A$. nidulans-system with the Neurospora crassa-system (DeMoss and Wegman 1965). Mutant class A of Aspergillus, lacking anthranilate synthetase activity, corresponds to mutant class tryp-2 in Neurospora. Locus $D$ of Aspergillus is analogous to locus tryp-4 in Neurospora, both influencing PR-transferase. Tryptophan synthetase is controlled by locus $B$ in Aspergillus and locus tryp-3 in Neurospora. Locus $C$ of Aspergillus corresponding to the tryp-1 locus in Neurospora, influences PRA isomerase and InGP synthetase activity as well as anthranilate synthetase.

The significance of mutant class $\mathrm{E}$ is unclear. Since all activities tested were present at the same levels as in the parental strain this class cannot, at present, be attributed to a specific enzyme defect. Furthermore, zone centrifugation experiments did not give any indication of a change in the physical nature of the enzymatically active protein components; the same activity bands were found as in the parental strain A160. RoBerTs (1967) suggests that the defect in the group $\mathrm{E}$ mutants may be in some biochemical reaction concerned with the metabolism of tryptophan rather than with its biosynthesis.

The occurrence of three activities, anthranilate synthetase, PRA isomerase and InGP synthetase, in a common band in zone centrifugation experiments in combination with the results of the enzymatic analysis of the mutant classes $\mathrm{A}$, $\mathrm{B}, \mathrm{C}$ and $\mathrm{D}$, demonstrates that the pattern of gene-enzyme relationships for the tryptophan pathway of $A$. nidulans is identical to that of $N$. crassa, but distinct from those found in Saccharomyces cerevisiae and Escherichia coli (Table 1).

While the zone centrifugation results suggest that anthranilate synthetase, PRA isomerase and InGP synthetase are associated with a single component in $A$. nidulans in analogy to the aggregate in $N$. crassa, proof of the occurrence of such an aggregate can only come from a more detailed biochemical study on the presumed aggregate.

Comparative studies of the tryptophan enzymes in a number of different fungi by means of zone centrifugation have demonstrated the occurrence of variety of 
enzyme aggregate patterns. Within certain groups of fungi identical aggregate types are found, but the groups differ from one another in the aggregate pattern (HütTER and DeMoss, in preparation). It is suggested that identical aggregate types result from similarities in genetic control, i.e., the same number of controlling loci and analogous interactions of the gene products. The similarities in the behaviour of $N$. crassa and $A$. nidulans underline the correctness of such an assumption.

The authors wish to express their appreciation to Dr. CLIve Roberts for supplying the strains and valuable information.

\section{SUMMARY}

The five tryptophan mutant classes in Aspergillus nidulans strain A160, A, B, $\mathrm{C}, \mathrm{D}$, and $\mathrm{E}$ were analyzed for enzymatic defects in the tryptophan pathway. Lesions in the $A$ locus exert their effect on anthranilate synthetase, locus $B$ controls tryptophan synthetase and representatives of mutant class D are deficient in PR-transferase activity. The action of gene $C$ is more complex; it not only controls the synthesis of an enzyme with PRA isomerase and InGP synthetase activity, but also influences the activity of anthranilate synthetase. Members of mutant class $\mathrm{E}$ had no deficiencies in any of the enzymatic activities tested; the significance of this locus is not understood. From these observations and the sedimentation behaviour of the tryptophan enzymes in zone centrifugation studies, it is inferred that gene-enzyme relationships for this pathway in $A$. nidulans is similar to that of $N$. crassa, but distinct from those of $S$. cerevisiae and $E$. coli. The similarities between $A$. nidulans and $N$. crassa support the assumption, suggested after comparative analyses of tryptophan pathway enzymes of a variety of fungi, that the identities in enzyme characteristics are caused by similar patterns of genetic control.

\section{LITERATURE CITED}

Ahmad, M., and D. G. CATCheside, 1960 Physiological diversity amongst tryptophan mutants in Neurosopora crassa. Heredity $15: 55-64$.

Bonner, D. M., J. A. DeMoss, and S. E. Milis, 1965 The evolution of an enzyme. pp. 305318. Evolving Genes and Proteins. Edited by V. Bryson, and H. J. Vogel. Academic Press, New York.

DeMoss, J. A., 1965 Biochemical diversity in the tryptophan pathway. Biochem. Biophys. Res. Comm. 18: 850-857.

DeMoss, J. A., and J. Wegman, 1965 An enzyme aggregate in the tryptophan pathway of Neurospora crassa. Proc. Natl. Acad. Sci. U.S. 54: 241-247.

Ensign, S., S. Kapd.AN, and D. M. Bonner, 1964 Purification and partial characterization of tryptophan synthetase from Neurospora crassa. Biochim. Biophys. Acta 81 : 357-366.

Iтo, J., and I. P. Crawford, 1965 Regulation of the enzymes of the tryptophan pathway in Escherichia coli. Genetics 52: 1303-1316.

Lowry, O. H., M. Rosenbrough, A. L. Farr, and R. J. Randald, 1951 Protein measurement with the folin phenol reagent. J. Biol. Chem. 193 : 265-275. 
Matsushiro, A., 1963 Specialized transduction of tryptophan markers in Escherichia coli K-12 by bacteriophage $\phi 80$. Virology $19: 475-482$.

Mortimer, R. K., and D. C. Hawthorne, 1966 Genetic mapping in Saccharomyces. Genetics 53 : $165-173$.

Roвerts, C. E., 1967 Genetic analysis of the tryptophan pathway in Aspergillus nidulans. Genetics 55: 233-239.

Vogel, H. J., 1956 A convenient growth medium for Neurospora (medium N). Microbial Gen. Bull. 13: 42-43.

WEGMAN, J., 1964 The tryptophan pathway of Neurospora crassa. Thesis, University of California, San Diego.

Wegman, J., and J. A. DeMoss, 1965 The enzymatic conversion of anthranilate to indolylglycerol phosphate in Neurospora crassa. J. Biol. Chem. 240: 3781-3788.

YANofskx, C., 1955 Tryptophan synthetase from Neurospora. pp. 233-238. Methods in Enzymology, Vol. 2. Edited by S. P. Colowxck, and N. O. KAPLAN. Academic Press, New York.

YANofsky, C., and E. S. LeNNox, 1959 Transduction and recombination study of linkage relationships among genes controlling tryptophan synthesis in Escherichia coli. Virology 8: 425-447. 